\title{
QUEIXAS IDENTIFICADAS EM CRIANÇAS E ADOLESCENTES ATENDIDOS PELO SERVIÇO DE PSICOLOGIA PEDIÁTRICA DE UM HOSPITAL UNIVERSITÁRIO
}

\author{
COMPLAINTS IDENTIFIED IN CHILDREN AND TEENAGERS ASSISTED BY A \\ PEDIATRIC PSYCHOLOGY SERVICE OF A UNIVERSITY HOSPITAL

\begin{abstract}
Rocha AC, Ferreira EAP. Queixas identificadas em crianças e adolescentes atendidos pelo serviço de psicologia pediátrica de um hospital universitário. Rev Bras Crescimento Desenvolv Hum. 2006;16(1):32-48.

Resumo: Este estudo descritivo apresenta a caracterização das queixas identificadas na clientela infanto-juvenil $(\mathrm{N}=62)$ atendida pelo serviço de Psicologia Pediátrica de um hospital universitário. Fez-se um levantamento de indicadores sócio-demográficos tanto das crianças e adolescentes como de seus cuidadores; realizou-se ainda uma análise estatística descritiva acerca dos atendimentos conduzidos, considerando-se itens como procedência da população, encaminhamentos realizados e queixas (principais e secundárias) mais freqüentes. Verificou-se que alguns achados corroboram a literatura, como o elevado número de meninos que buscam o atendimento, o índice de desistência e tipos similares de queixas. Observou-se ainda um uso demasiado de práticas parentais coercitivas, que apontam para a questão da violência doméstica. Estes achados foram iniciais e podem contribuir para a implementação de um serviço de Psicologia Pediátrica mais estruturado, assim como subsidiar pesquisas posteriores que utilizem análises estatísticas correlacionais.
\end{abstract}

Palavras-chave: Psicologia pediátrica. Indicadores sócio-demográficos. Violência doméstica.

\section{INTRODUÇÃO}

Inicialmente, a psicoterapia comportamental infantil esteve bastante relacionada ao behaviorismo metodológico, o qual utilizava estratégias e métodos experimentais, medidas objetivas e quantificáveis mesmo na prática clínica. No processo de análise da queixa, comportamentos encobertos da criança, variáveis contextuais e a própria relação que os pais estabeleciam com seus filhos, não eram enfatizados. De acordo com Conte e Regra ${ }^{1}$, a proposta de intervenção baseava-se na seleção de procedimentos comportamentais específicos para aquele problema ou então na utilização de princípios de aprendizagem, os quais geralmente objetivavam "extinguir os comportamentosqueixa e aumentar a probabilidade de ocorrência dos comportamentos incompatíveis" (p.83). Em casos com várias queixas, atuava-se apenas sobre uma e, após a averiguação de que as mudanças esperadas estavam ocorrendo, então se agia sobre a outra queixa. Cabia ao terapeuta a orientação dos mediadores, em geral os pais da criança, na aplicação dos procedimentos programados ${ }^{1}$.

\footnotetext{
Estudo realizado como Trabalho de Conclusão do Curso de graduação em Psicologia pela primeira autora, com a orientação da segunda autora. Universidade Federal do Pará, Departamento de Psicologia Social e Escolar. E-mail: eleonora@ufpa.br
} 
Este tipo de atuação recebeu muitas críticas na medida em que, para a obtenção do sucesso terapêutico, o atendimento precisava ser prolongado. Além disso, o papel da relação terapêutica não era analisado; entretanto, hoje se sabe que ela é uma importante variável na obtenção de resultados ${ }^{1}$.

Apesar das inúmeras críticas, não se pode negar a contribuição trazida à psicoterapia comportamental como um todo e, principalmente à infantil, "a instalarem-se como práticas profissionais sistemáticas, éticas e cientificamente sustentáveis" (p.84) ${ }^{1}$.

A psicoterapia comportamental infantil foi se modificando progressivamente. Inicialmente foi proposto o modelo diádico, no qual a intervenção terapêutica dava-se no contexto clínico, a partir da interação entre, apenas, cliente e terapeuta. Esse modelo também sofreu críticas e modificações ${ }^{2}$.

Atualmente, um dos modelos de intervenção terapêutica mais difundidos é o modelo triádico, o qual, proposto por Tharp e Wetzel em $1969\left(\right.$ apud $\left.^{2}\right)$, tem como pressuposto básico a participação de pelo menos três pessoas: a criança (cliente), o terapeuta e um mediador. Será principalmente sobre esse mediador que a atuação do terapeuta terá maior direcionamento, pois, para o modelo triádico, as mudanças comportamentais do cliente serão obtidas através de manipulações ambientais realizadas por aqueles que dispõem dos reforçadores - os mediadores $^{2}$.

Silvares ${ }^{2}$, considerando a premissa do modelo triádico conclui:

“Assim, os pais, mediadores ideais, foram concebidos, dentro do modelo triádico, como os que deveriam receber a orientação psicológica no sentido da mudança dos padrões comportamentais de seus filhos. Para que tal mudança fosse possível, é claro, também a interação pai-filho deveria ser alterada e era nesse sentido que a intervenção terapêutica se dava" (p.235).
Marinho e col. ${ }^{3}$ ratificam a idéia de que o próprio modelo triádico vem sofrendo ampliações, na medida em que hoje este modelo abrange várias formas de intervenção comportamental com famílias. Estas pesquisadoras discutem a proposta de Tiedeman e Johnston em 1992 de que, independentemente dos modelos de intervenção adotados - sejam eles, psicoterapia parental, orientação parental mais psicoterapia infantil, e treinamento de pais - faz-se necessário ampliar o foco do comportamento-problema e desenvolver habilidades parentais no aprendizado e ensino de comportamentos mais adaptativos para seus filhos pois algumas competências infantis, como a assertividade, estão relacionadas à ocorrência de respostas dos pais de aceitação e expressão de sentimentos. Silvares ${ }^{2}$ também discute a ampliação do modelo triádico, enfatizando que, em estudos mais recentes, as intervenções têm se estendido a elementos como escola, comunidade e família.

Marinho ${ }^{4}$ chama a atenção para a relevância de intervenções efetivas junto a crianças e adolescentes com problemas, como medidas preventivas e atenuantes de sofrimento presente e futuro. A autora salienta que problemas comportamentais infantis são, em parte, desenvolvidos e mantidos por interações mal-adaptativas entre pais e criança e é nesse sentido que os primeiros também têm sido alvo da intervenção terapêutica.

"Quando, nas sessões, se ensina os pais a avaliarem positivamente mesmo os comportamentos adequados aparentemente mais simples emitidos pela criança (como escovar os dentes antes de dormir, ser atencioso, alegre, cooperar), eles deixam de ver estas atitudes como se fossem "naturais" ou "obrigações", para as considerarem méritos de sua criança, comportamentos adequados que ela aprendeu. Decorrente disto, passam também a se perceberem como pais mais eficientes do que achavam que fossem" (p. 181).

Muitos estudos têm enfatizado que a 
manifestação de problemas de comportamento em crianças está significativamente relacionada às práticas educativas utilizadas pelos pais. Queixas como agressividade, impulsividade, desobediência e comportamento delinqüente estão geralmente associadas a práticas educativas parentais de caráter coercitivo ${ }^{5}$.

Alvarenga ${ }^{5}$ descreve algumas práticas coercitivas, tais como: punição verbal, caracterizada pelo "uso de estímulos aversivos verbais como repreensões, proibições ou demonstrações de desaprovação em relação ao comportamento" (p.56); ameaça de punição, ou seja, "regras que descrevem conseqüências aversivas arbitrárias para o comportamento que a criança está emitindo e que a mãe pretende suprimir" (p.56); privação/castigo, caracterizado pelo "uso de punições negativas, como castigos ou privações" (p.56); coação física, na qual há a emissão de “comportamentos não verbais da mãe que forçam fisicamente a criança a se comportar de determinada forma" (p.56); e punição física, caracterizada pelo "uso de estímulos aversivos físicos para suprimir o comportamento" (p.56).

Uma educação baseada em excessivo controle coercitivo pode trazer para o indivíduo conseqüências negativas a curto e longo prazo, como baixa auto-estima, efeitos colaterais da punição como respostas ansiogênicas diante de situações consideradas simples pela maioria das pessoas, pouco engajamento no ambiente, o que tende a reduzir ainda mais a probabilidade de obtenção de reforçadores positivos, além de poder funcionar como estímulo modelo, o que possibilita a ocorrência de interações agressivas, ou seja, baseadas também em controle coercitivo. Sidman ${ }^{6}$ descreve a punição do seguinte modo:

"Sempre que vemos uma ação produzindo a perda de um reforçador positivo, ou a produção de um reforçador negativo, dizemos que a ação está sendo punida. [ ] Eu defino estas duas contingências de punição - a perda de reforçadores positivos e a pro- dução de reforçadores negativos - como coercitivas; punição é a segunda maior categoria de controle coercitivo" (p.59).

Alvarenga $^{5}$ adverte para o fato de que, em algumas circunstâncias, a punição pode estar associada a reforçadores quando, por exemplo, "uma prática punitiva é seguida pelo arrependimento ou demonstrações de culpa dos pais" (p.57), e dependendo do nível de privação de afeto e atenção dos pais em que a criança se encontra, comportar-se inadequadamente torna-se um modo de obtenção desses reforçadores. E se esta for a única ou principal forma de ganhar atenção dos cuidadores, estes comportamentos inadequados tendem a aumentar de freqüência, na medida em que estão sendo reforçados positivamente, superando "os efeitos das conseqüências que, de outra forma, serviriam como estímulos aversivos" (p.57). A autora ainda exemplifica com uma situação que pode ser comum, na qual uma mãe ao brincar com seu filho ignora os comportamentos adequados deste (extinção), e eventualmente reforça seus comportamentos inadequados.

Excesso de controle coercitivo pode trazer conseqüências negativas para o indivíduo e para o meio em que interage; em contrapartida, ausência de limites acarreta irresponsabilidade, a qual pode culminar em comportamentos de delinqüência. Segundo Canaan-Oliveira e cols. ${ }^{7}$ "estabelecer limites é ensinar à criança o que é e o que não é permitido" (p.53). Além disso,

"a falta de limites implica a ausência de conseqüências para o comportamento indesejável da criança, o que acarreta inúmeros problemas. Quando os limites não são estabelecidos, a criança sai ilesa das situações, o que faz com que seja quase impossível para ela prestar atenção às palavras dos outros e ouvir instruções (conselhos, sugestões etc.). Quando não consegue ouvir instruções, a criança dificilmente as segue, o que dificulta muito as suas aprendizagens e a sua capacidade de adaptação ao ambiente” (p.53). 
Compreender as fontes de controle de um dado comportamento é importante para alterar a probabilidade de ocorrência deste, assim como fornecer conseqüências mais positivas para o indivíduo, produzindo sentimentos de segurança e satisfação.

Pode-se considerar como formas de intervenção dentro do modelo triádico: (a) treino de pais em manejo de contingências, no qual não há a participação ativa da criança na manipulação das contingências alteradoras de seu comportamento; este procedimento é indicado para casos em que a criança é muito pequena ou em que encontre-se muito comprometida; (b) contrato de contingências, no qual a participação da criança é indispensável, pois há o estabelecimento de acordos (unilaterais ou bilaterais) entre a criança e outros membros, com especificações das conseqüências para o cumprimento ou não das cláusulas ou tarefas contidas no contrato; (c) treino familiar em resolução de problemas, o qual diz respeito a alterações significativas no padrão de interação entre os membros da família².

Marinho e col. ${ }^{3}$ apresentam um estudo no qual adotaram-se três modelos de intervenção: (a) psicoterapia parental, na qual não houve a participação da criança, com enfoque nos sentimentos, dúvidas e nas dificuldades dos pais na educação dos filhos, sendo abordados temas diversificados em sessões grupais; (b) orientação parental mais psicoterapia infantil, na qual ocorriam sessões grupais junto aos pais, paralelas a atendimentos com os filhos; e (c) treinamento de pais, modelo aplicado considerado mais efetivo, o qual era de curta duração e seu foco era sobre a compreensão dos pais acerca de princípios de aprendizagem, aquisição de habilidades importantes na interação com os filhos, como a observação e o reforçamento diferencial, e na realização de análises funcionais de seus próprios comportamentos e dos comportamentos dos filhos. Neste estudo a maioria das crianças era do sexo masculino
(68,7\%) e filho primogênito (75\%).

Bernardes-da-Rosa e cols. ${ }^{8}$ apresentaram um estudo que caracterizou o atendimento psicológico prestado a 25 crianças, em contexto de clínica-escola, com queixas de dificuldades escolares. Segundo as autoras, estudos brasileiros que caracterizam serviços de psicologia indicam que a maioria da população atendida é do sexo masculino, e que as principais queixas estão relacionadas a dificuldades escolares e a comportamentos explícitos, como a agressividade e a agitação psicomotora. De acordo com as autoras, esses estudos ainda evidenciam um elevado índice de desistência dos atendimentos, e chamam a atenção para a importância do desenvolvimento de estratégias que minimizem esse índice de abandono.

No Brasil, nota-se que os estudos sobre a caracterização de serviços de psicologia ocorrem em contextos de clínica-escola, indicando uma escassez de literatura voltada à caracterização de atendimentos psicológicos realizados em hospitais universitários.

Em contextos de atenção à saúde, o campo da psicologia vem trazendo importantes contribuições, pois em muitas doenças crônicas, como o diabetes e disfunções renais, é necessário o desenvolvimento e a manutenção de novos comportamentos, os quais podem implicar em profundas alterações na rotina de vida do indivíduo e de sua família, principalmente no caso de crianças e adolescentes ${ }^{9}$.

A realidade dos hospitais universitários brasileiros é diversificada, e a história de tradição desses hospitais relaciona-se ao desenvolvimento e estruturação de programas na área médica mais especializados. Esta realidade pode ser observada ao se consultar sites de hospitais universitários em diversas regiões do Brasil e comparar a própria quantidade de programas especializados e serviços oferecidos por algumas dessas instituições ${ }^{10,11,12,13 .}$

Do mesmo modo, a parceria entre a pediatria e a psicologia também está relacionada 
a uma estruturação na área médica. A própria evolução e especialização das ciências médicas permite a existência de subespecialidades. Hoje a pediatria, com longa tradição generalista, também especifica seu campo de atuação voltando-se para uma atuação ainda mais especialista, como a neuropediatria, gastroenterologia pediátrica, cardiologia pediátrica e endocrinologia pediátrica.

Isso significa que a introdução e a especialização de áreas de atuação da psicologia pediátrica depende de pré-requisitos, como a estruturação e sistematização de programas dentro da própria área médica.

Roberts ${ }^{14}$ apresenta uma investigação histórica da inserção da psicologia no campo da pediatria. Inicialmente, os problemas trazidos como queixa eram muito diversificados, como problemas de aprendizagem, comportamentos opositores e agressivos dirigidos à família e à escola, problemas conjugais entre os pais das crianças, dificuldades relacionadas ao sono, à alimentação e funções de eliminação, medos específicos, e comprometimentos orgânicos. Isso sugere que a evolução e o refinamento de um serviço psicológico dentro do campo pediátrico ocorrem na medida em que há uma compreensão inicial da própria clientela que busca pelo serviço e da diversidade de fatores que interferem no funcionamento do indivíduo.

A Psicologia Pediátrica é um campo interdisciplinar voltado para a totalidade de questões de desenvolvimento físico e mental, saúde e enfermidade que afetam crianças, adolescentes e famílias. [Ela engloba] uma ampla variedade de tópicos que exploram a relação entre o bem-estar psicológico e físico de crianças e adolescentes, incluindo: compreensão, avaliação e intervenção com transtornos de desenvolvimento; avaliação e tratamento de problemas comportamentais $e$ emocionais e concomitantes de doenças e enfermidades; o papel da psicologia na medicina pediátrica; a promoção de saúde e desen- volvimento; e a prevenção de enfermidades e danos entre crianças e jovens $\left({ }^{14}, p .7\right)$.

Esta definição permite considerar que no processo de saúde/doença está envolvida uma complexidade de comportamentos, os quais podem estar relacionados tanto a estratégias preventivas como voltados à reabilitação do indivíduo.

Serviços especializados de psicologia pediátrica estão disponíveis em alguns hospitais universitários, e mostram-se relevantes ao atuarem mais diretamente em doenças crônicas, como o diabetes e a asma9 .

Embora se especialize o serviço, o profissional de psicologia, ao atuar em ambulatório de pediatria, ainda assim deverá estar atento às múltiplas variáveis que estão atuando de modo significativo no processo de adoecimento da criança e do adolescente. Este estudo descritivo apresenta a caracterização das queixas identificadas na clientela atendida pelo serviço de Psicologia Pediátrica de um hospital universitário. Foi realizado com o objetivo de identificar variáveis relevantes para o planejamento de procedimentos de intervenção voltados a crianças e adolescentes encaminhados a serviços de Psicologia Pediátrica.

\section{MÉTODO}

\section{Participantes}

Participaram deste estudo 62 pacientes atendidos pelo serviço de Psicologia Pediátrica de um hospital universitário (HU) na cidade Belém (Pará), no período de janeiro de 2002 a junho de 2003. Esta amostra era composta de 55 crianças (faixa etária de 1 a 12 anos) e 7 adolescentes (13 a 16 anos) de ambos os se$\mathrm{xos}($ masculino $=42 \mathrm{e}$ feminino $=20)$. Estes pacientes chegaram ao serviço de Psicologia Pediátrica através de encaminhamentos de outros serviços disponíveis no hospital, por demanda voluntária ou por encaminhamentos fornecidos 
por outros serviços de saúde ou estabelecimentos disponíveis na cidade. OHU é mantido com recursos do Sistema Único de Saúde (SUS), conta com diversos profissionais e especialidades médicas, e disponibiliza à população atendimentos ambulatoriais e de hospital-dia, além da realização de exames e procedimentos especializados.

\section{Materiais e recursos utilizados para a coleta de dados}

Neste estudo foram utilizados: roteiro de entrevista específico para crianças e adolescentes (protocolo desenvolvido pelo próprio serviço de Psicologia Pediátrica) preenchido com dados sócio-demográficos dos pacientes, história de vida e queixas iniciais; registro dos atendimentos conduzidos pelos estagiários de Psicologia a cada sessão; e guias de encaminhamento endereçadas ao serviço de psicologia pediátrica. Esse material compunha o prontuário interno de cada participante.

\section{Procedimento}

A condução deste estudo foi dividida em duas etapas:

\section{Etapa 1. Levantamento e organização dos dados}

Inicialmente foi realizado um levantamento dos prontuários internos, arquivados no Serviço de Psicologia Pediátrica do HU, referentes ao período de janeiro de 2002 a junho de 2003. As informações coletadas de cada participante, referentes a dados sócio-demográficos, queixas, procedência e condução dos atendimentos, foram organizadas em tabelas. Com o objetivo de corroborar, corrigir, esclarecer ou complementar estas informações, foram realizadas entrevistas com os nove estagiários res- ponsáveis pelos 62 casos atendidos no período a que se refere este estudo.

\section{Etapa 2. Análise dos dados}

Após o levantamento dos dados, foram feitas análises estatísticas descritivas acerca das características sócio-demográficas, da procedência, encaminhamentos realizados e resolutividade dos encaminhamentos e dos atendimentos.

A partir dos registros dos atendimentos e das entrevistas conduzidas, as queixas (principais e secundárias) foram agrupadas em nove categorias: (1) dificuldades em habilidades sociais, (2) dificuldades escolares, (3) violência doméstica, (4) alterações orgânicas, (5) alterações em hábitos de rotina, (6) dificuldades de adesão ao tratamento, (7) dificuldades conjugais dos pais, (8) dificuldades relacionadas à sexualidade e (9) outros. Dentre as queixas, aquelas que fizeram referência à violência doméstica mereceram destaque devido à condição de risco para a saúde da criança, sendo agrupadas em quatro subcategorias: (1) violência física (tipo 1 e tipo 2), (2) violência predominantemente emocional, (3) violência por negligência e (4) violência sexual, para as quais também foi realizada uma análise.

Os resultados obtidos foram organizados em tabelas e gráficos, e discutidos com base no referencial teórico analítico-comportamental e à luz da literatura da área da saúde da criança e do adolescente.

\section{RESULTADOS}

\section{Caracterização Sócio-Demográfica}

\section{a) Das crianças e adolescentes}

A Tabela 1 apresenta a distribuição dos participantes por sexo e faixa etária.

Quanto à ordem de nascimento, os dados 
Tabela 1: Distribuição dos participantes por sexo e faixa etária

\begin{tabular}{ccccccc}
\hline Faixa Etária & $\begin{array}{c}\text { Sexo } \\
\text { masculino }\end{array}$ & $\%$ & $\begin{array}{c}\text { Sexo } \\
\text { Feminino }\end{array}$ & $\%$ & Total & $\%$ \\
\hline $0-2$ anos & 03 & $4,8 \%$ & 02 & $3,2 \%$ & 05 & $8,0 \%$ \\
$3-6$ anos & 17 & $27,4 \%$ & 02 & $3,2 \%$ & 19 & $30,6 \%$ \\
$7-10$ anos & 15 & $24,2 \%$ & 09 & $14,5 \%$ & 24 & $38,7 \%$ \\
$11-14$ anos & 07 & $11,3 \%$ & 05 & $8,0 \%$ & 12 & $19,3 \%$ \\
$15-17$ anos & 0 & $0 \%$ & 02 & $3,2 \%$ & 02 & $3,2 \%$ \\
$\Sigma$ & 42 & $68 \%$ & 20 & $32 \%$ & 62 & $100 \%$ \\
\hline
\end{tabular}

indicaram que dos 62 participantes, 27 eram filhos caçulas, 21 eram filhos primogênitos, 8 eram filhos únicos e 6 eram filhos intermediários.

Neste estudo, considerou-se a idade de 3 anos como referência para início da escolaridade, haja visto o elevado índice de crianças freqüentando a educação infantil, embora não seja obrigatória. Desse modo, contabilizou-se que dos 62 participantes, 57 estavam em idade escolar. Dentre estes, 1 ainda não estudava (idade de 4 anos), 15 estavam na Educação Infantil (maternal, jardim I e II, e alfabetização), 28 cursavam séries do Ensino Fundamental I ( $1^{\mathrm{a}}$ à $4^{\mathrm{a}}$ série do $1^{\circ}$ grau), 7 estavam no Ensino Fundamental II ( $5^{\mathrm{a}}$ à $8^{\mathrm{a}}$ série do $1^{\circ}$ grau), 2 participantes estavam cursando o Ensino Médio (antigo $2^{\circ}$ grau), e 4 não informaram.

A Figura 1 apresenta o índice de correspondência e de atraso na correspondência entre idade e série escolar. A análise da correspondência série-idade foi feita com base nas normas estipuladas pela $\mathrm{LDB} / \mathrm{MEC}$, tomando a idade de 3 anos como referência para o ingresso na educação infantil e 7 anos para a conclusão da primeira série do ensino fundamental. Os dados obtidos por meio da análise dos

Figura 1: Correspondência entre nível de escolaridade e idade da população.

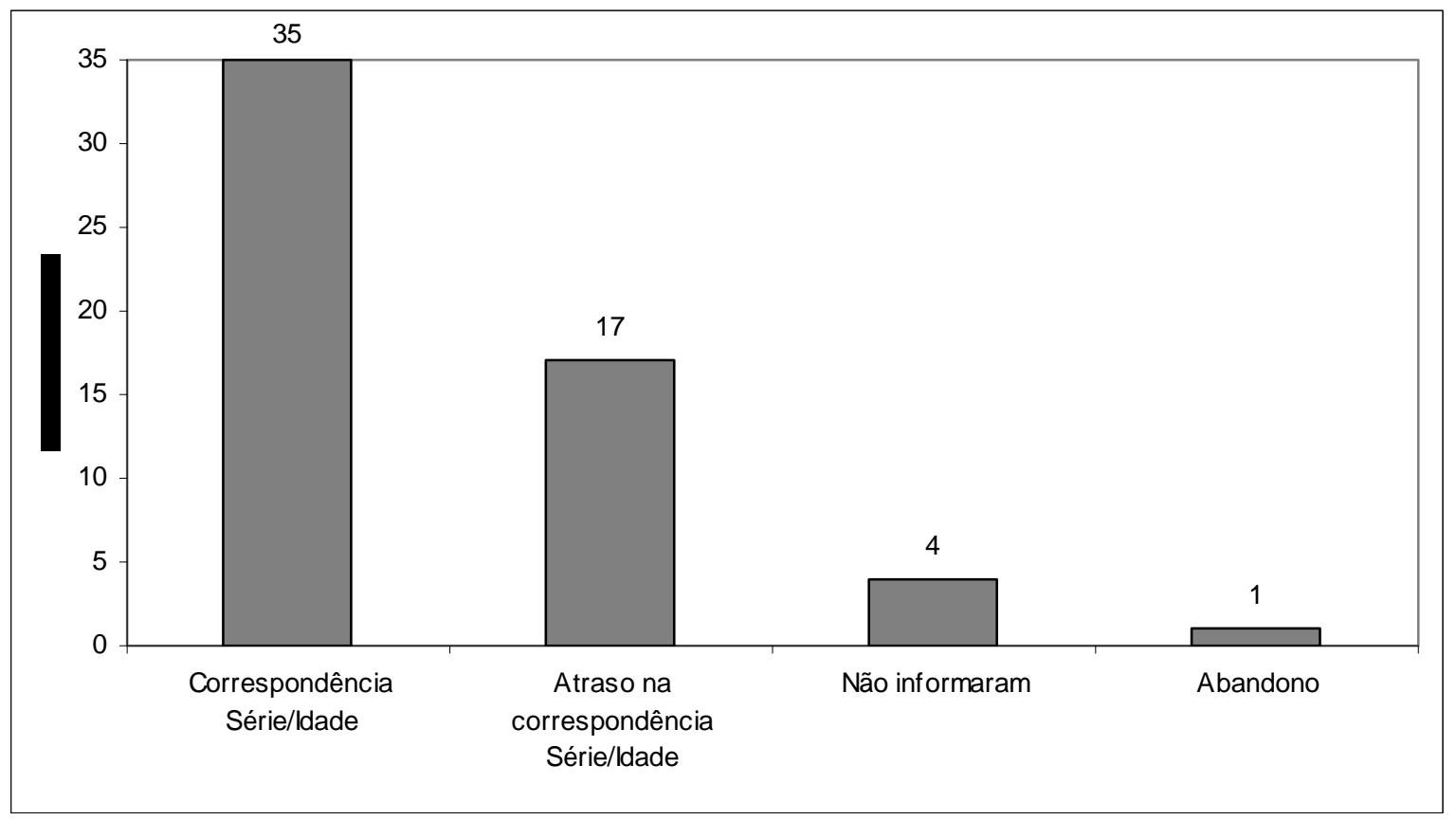


prontuários e das entrevistas com os estagiários sugerem que a maioria das crianças e adolescentes atendidos no período em que este estudo foi realizado estava cursando a série correspondente à sua idade cronológica, tanto na educação infantil, quanto no ensino fundamental.

A clientela atendida morava em Belém e seus arredores (Grande Belém), sendo que pelo menos $61 \%$ habitava em um dos dois bairros mais próximos ao Hospital Universitário, os quais caracterizavam-se pelo baixo poder aquisitivo dos moradores e problemas em sua infra-estrutura (p.e. saneamento básico e segurança).

\section{b) Dos cuidadores}

O levantamento feito acerca do cuidador principal das crianças e adolescentes atendidos indicou que a maioria era a mãe biológica $(n=45$, ou 73\%), 4 eram mães adotivas, 3 pais biológicos, 4 avós (maternas ou paternas), 5 cuidadores tinham outros graus de parentesco, e 1 não tinha parentesco com o participante.

As ocupações dos cuidadores foram agrupadas nas seguintes categorias: do lar $(\mathrm{n}=23)$, trabalho informal $(\mathrm{n}=10)$, assalariado $(n=8)$, estudante $(n=6)$, funcionário público $(n=3)$, profissional da saúde $(n=3)$ e aposentado $(n=2)$. Para 7 participantes não havia no prontuário o registro da ocupação do cuidador principal.

\section{Caracterização dos Atendimentos}

A procedência dos casos foi dividida em interna, externa e espontânea. Considerou-se como de procedência interna aqueles pacientes encaminhados por profissionais do $\mathrm{HU}$ ou por meio de atendimentos em sala de espera ou pesquisas que estavam sendo realizadas no período em questão. Os casos de procedência externa foram aqueles pacientes encaminhados de outros serviços de saúde ou estabelecimentos existentes na comunidade. Como demanda espontânea foram incluídos aqueles pacientes que eram matriculados no HU e procuraram espontaneamente pelo atendimento de psicologia.

Foi registrado que 10 casos chegaram ao atendimento psicológico através de encaminhamentos externos ao HU (16\%), 16 casos eram de demanda espontânea (26\%), e a maioria, 36 casos, foi encaminhada por diferentes especialidades médicas, profissionais e programas de sala de espera e de pesquisa que estavam sendo conduzidos no HU (58\%).

Dos 36 casos classificados como de procedência interna, 13 pacientes foram encaminhados pelo serviço de Pediatria, 5 chegaram ao atendimento com a psicologia através de programas de sala de espera, 4 foram encaminhados por outros serviços de Psicologia presentes no hospital, 3 pelo serviço de neuropediatria, 3 por pesquisa que estava sendo conduzida, 2 pelo Projeto Caminhar [especializado no atendimento a crianças com problemas de desenvolvimento], 2 pelo Serviço Social, 2 pela Nutrição, 1 pela Psiquiatria e 1 caso encaminhado pelo serviço de Endocrinologia.

Quanto à procedência externa, 3 casos foram encaminhados pelo Conselho Tutelar, 3 por serviços de Psicologia de outros hospitais públicos da cidade de Belém, 2 pela Coordenação Estadual de Educação Especial e 2 casos por escolas públicas da cidade.

No decorrer dos atendimentos, de acordo com a avaliação do caso feita pelo estagiário e supervisor, eram fornecidos encaminhamentos aos pacientes. Dos 62 casos conduzidos, 30 obtiveram um ou mais tipos de encaminhamento (48\%) e para 32 casos não se considerou a necessidade de encaminhamentos $(52 \%)$.

Estes encaminhamentos poderiam ser destinados a especialidades médicas, projetos e serviços ofertados no espaço físico do $\mathrm{HU}$, além de órgãos e serviços especializados disponibilizados fora do HU. Foram fornecidos 46 encaminhamentos, e destes, 26 foram considerados efeti- 
vos na medida em que os pacientes ou cuidadores compareceram ao destino dos encaminhamentos. Registrou-se ainda 11 não comparecimentos e 9 encaminhamentos sem obtenção de informação a respeito de sua resolutividade. A Figura 2 apresenta os destinos dos encaminhamentos realizados e sua resolutividade.

Os encaminhamentos foram endereçados, principalmente, às seguintes especialidades, projetos, órgãos e serviços:

a) Projeto "Caminhar": Projeto realizado no HU em parceria com a Prefeitura Municipal de Belém, o qual atende crianças com problemas de desenvolvimento, dispondo de especialidades como fonoaudiologia, terapia ocupacional e neuropediatria.

b) Grupo de Pais “Conviver": Grupo de orientação e acompanhamento à família, coordenado pelos estagiários e supervisora do serviço de psicologia pediátrica, e destinado a cuidadores e familiares das crianças e adolescentes em atendimento, o qual reunia-se semanalmente para discussões e orientações acerca da relação pais e filhos. c) NPJ / CCJ: Núcleo de Práticas Jurídicas e Centro de Ciências Jurídicas, órgãos vinculados à Universidade Federal do Pará, os quais prestam serviços gratuitos de orientação e assessoria jurídica a pessoas de baixa renda.

d) Conselho Tutelar: Atende famílias com problemas conjugais ou entre pais e filhos, procurando zelar pelos direitos da criança e do adolescente garantidos no Estatuto da criança e do adolescente (ECA). Pode requisitar trabalhos na área da saúde, educação, segurança.

e) Outros: nesta categoria estão incluídos alguns serviços oferecidos pelo HU como oftalmologia, clínica médica, serviço social, nutrição, otorrinolaringologia, bem como serviços encontrados na comunidade como a Coordenação Estadual de Educação Especial (COEES), escolas e programas mantidos no Hospital da Fundação Santa Casa de Misericórdia do Pará.

Dentre os 62 casos atendidos, 21 compareceram de uma até duas vezes aos atendimentos agendados pelo serviço de Psicologia Pediátrica, 19 casos tiveram contabilizados entre três e quatro sessões, 2 somaram entre cin-

Figura 2: Destino dos encaminhamentos realizados pelo serviço de Psicologia Pediátrica do HU e sua resolutividade.

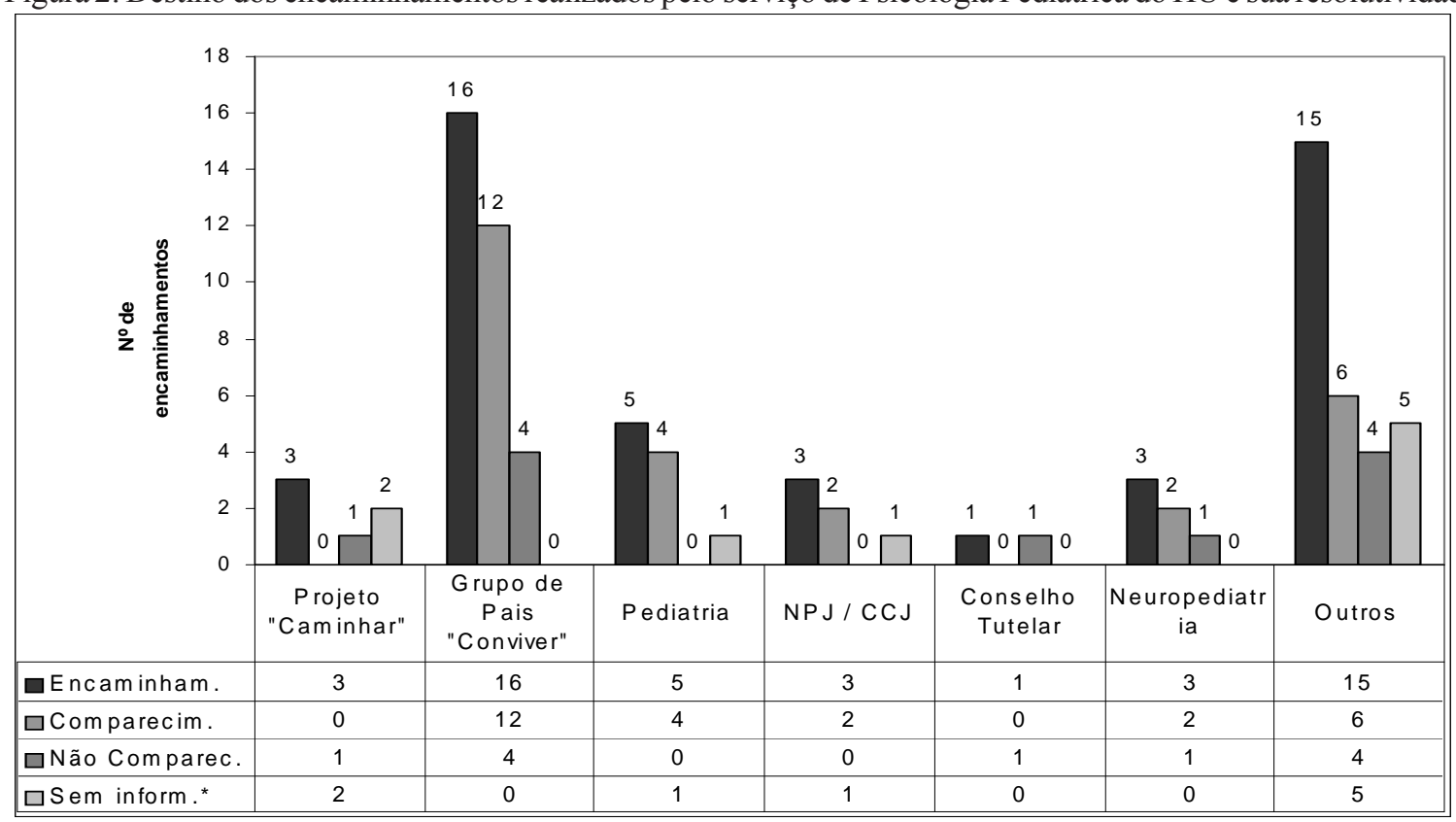

* Nota: A categoria “Sem informação” significa que não havia registro no prontuário, nem o estagiário tinha a informação acerca do comparecimento ou não do participante ao destino do encaminhamento. 
co e seis atendimentos, e os outros 20 casos tiveram sete ou mais sessões. Quanto a resolutividade desses casos, foram registrados 9 encerramentos, 23 abandonos e 30 casos em andamento à época deste estudo.

As queixas trazidas pelos cuidadores no início e no decorrer dos atendimentos foram diversificadas. Para este estudo, as queixas investigadas, tanto as principais quanto as secundárias, foram agrupadas em 9 categorias. Considerou-se como queixas principais aquelas relatadas no primeiro atendimento, sendo consideradas como a principal justificativa para a busca do serviço. Como queixas secundárias considerou-se outras dificuldades relatadas pelo cuidador ou identificadas pelo estagiário ao longo das sessões. Na definição das 9 categorias de queixas foram utilizados os termos que haviam sido referidos pelos cuidadores e estagiários na descrição das queixas que demandaram $\mathrm{o}$ atendimento, apresentadas a seguir.

1. Dificuldades em Habilidades Sociais: comportamentos opositores (impulsividade, rebeldia, desobediência, agressividade, mentiras, não seguimento de regras, baixa tolerância à frustração, irritação, comportamentos de birra, possessividade, brigas com pares/irmãos, roubo, fuga de casa, teimosia, ameaças e comportamentos autolesivos), competitividade, timidez, medo e/ou fobias, ansiedade, tiques (manias, cacoetes), isolamento, pouca interação social, passividade, nervosismo, sintomas depressivos e comportamentos infantilizados.

2. Dificuldades Escolares: problemas de aprendizagem, desinteresse pelo estudo, baixo rendimento escolar, dificuldade de atenção/concentração, agitação e hiperatividade em contexto escolar.

3. Violência Doméstica: física (tipo I e II), predominantemente emocional, por negligência, e sexual.

4. Alterações Orgânicas: patologias (asma, diabetes), síndromes (Turner, Down, Prader Willi), paralisia cerebral, dores de cabeça, convulsão, desmaios, crises de ausência, proble- mas motores, de audição e fala.

5. Alterações em Hábitos de Rotina: enurese, encoprese, alterações no ciclo sono/vigília (insônia, agitação, sonolência), alterações em comportamentos alimentares (compulsão, restrição alimentar, baixo peso).

6. Dificuldades de Adesão ao Tratamento: baixa adesão à dieta, a medicamentos, não resposta ao tratamento, dificuldades na aquisição do medicamento, problemas com a mudança de medicamento.

7. Dificuldades Conjugais: brigas entre o casal, divórcio, separação judicial e questões referentes à pensão alimentícia, desde que afetando o comportamento da criança ou adolescente.

8. Dificuldades relacionadas à Sexualidade: dúvidas e problemas relacionados à sexualidade da criança ou adolescente.

9. Outros: envolvimento com drogas, prostituição, adoção, "má influência do namorado" (sic), olhar diferente e estranho.

A Figura 3 apresenta a freqüência das queixas principais e secundárias.

O item violência doméstica mereceu destaque neste trabalho na medida em que foi uma variável freqüentemente identificada no transcurso dos atendimentos; além disso, foi utilizada como uma das principais formas de controle (coercitivo) de comportamento por parte de cuidadores e/ou familiares das crianças e adolescentes deste estudo. Foram variados os tipos de violência relatados pelas crianças, adolescentes e cuidadores; e, com base nestes relatos e na literatura ${ }^{15}$, identificaram-se quatro categorias explicitadas a seguir:

1) Violência Física: Caracterizada por contato físico direto com o corpo do indivíduo, subdividida em:

- Tipo I: Caracterizada por episódios de agressão física, sem a utilização de objetos, e sem ameaça explícita à vida do indivíduo. Pode vir acompanhada de violência emocional.

- Tipo II: Caracterizada por episódios de agressão física, intensos e/ou freqüentes, por meio da utilização de objetos, com ameaça à vida do 
Figura 3: Freqüência das queixas principais e secundárias

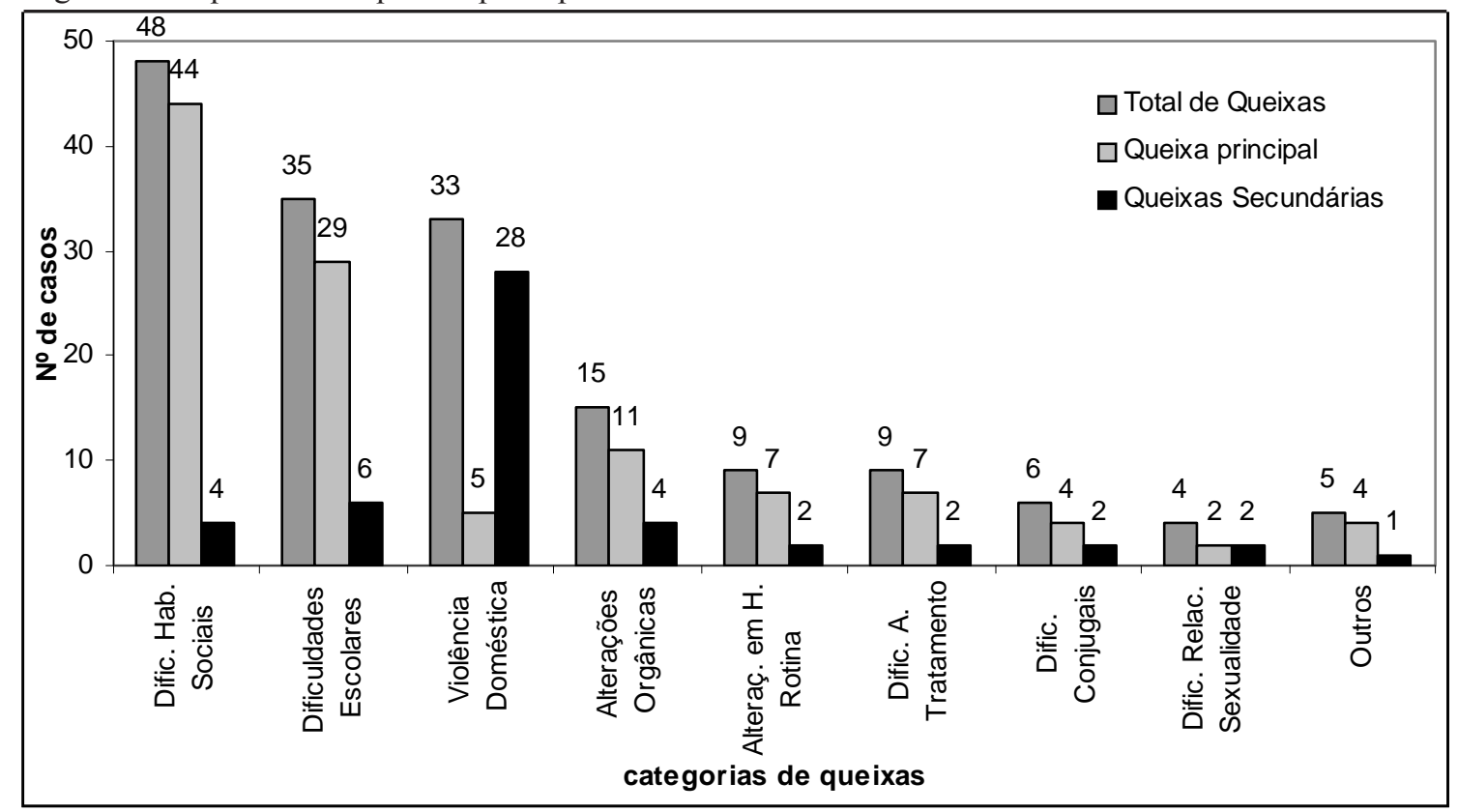

indivíduo. Nesse tipo de agressão, a violência emocional está presente, podendo também vir acompanhada de violência por negligência.

2) Violência predominantemente Emocional: Caracterizada por agressões verbais intensas e freqüentes, não acompanhadas de violência física, que possam diminuir a auto-estima do indivíduo, com a utilização de termos pejorativos, humilhações e ameaças.
3) Violência por Negligência: Caracterizada por displicência ou descaso do cuidador principal quanto às funções básicas de proteção, saúde, higiene, educação e bem-estar, não acompanhada de violência física.

4) Violência Sexual: Caracterizada por, no mínimo, um episódio de abuso sexual, podendo vir acompanhada de episódios de violência física, emocional ou por negligência.

Figura 4: Freqüência dos principais tipos de violência doméstica, categorizados a partir de registros e relatos dos estagiários.

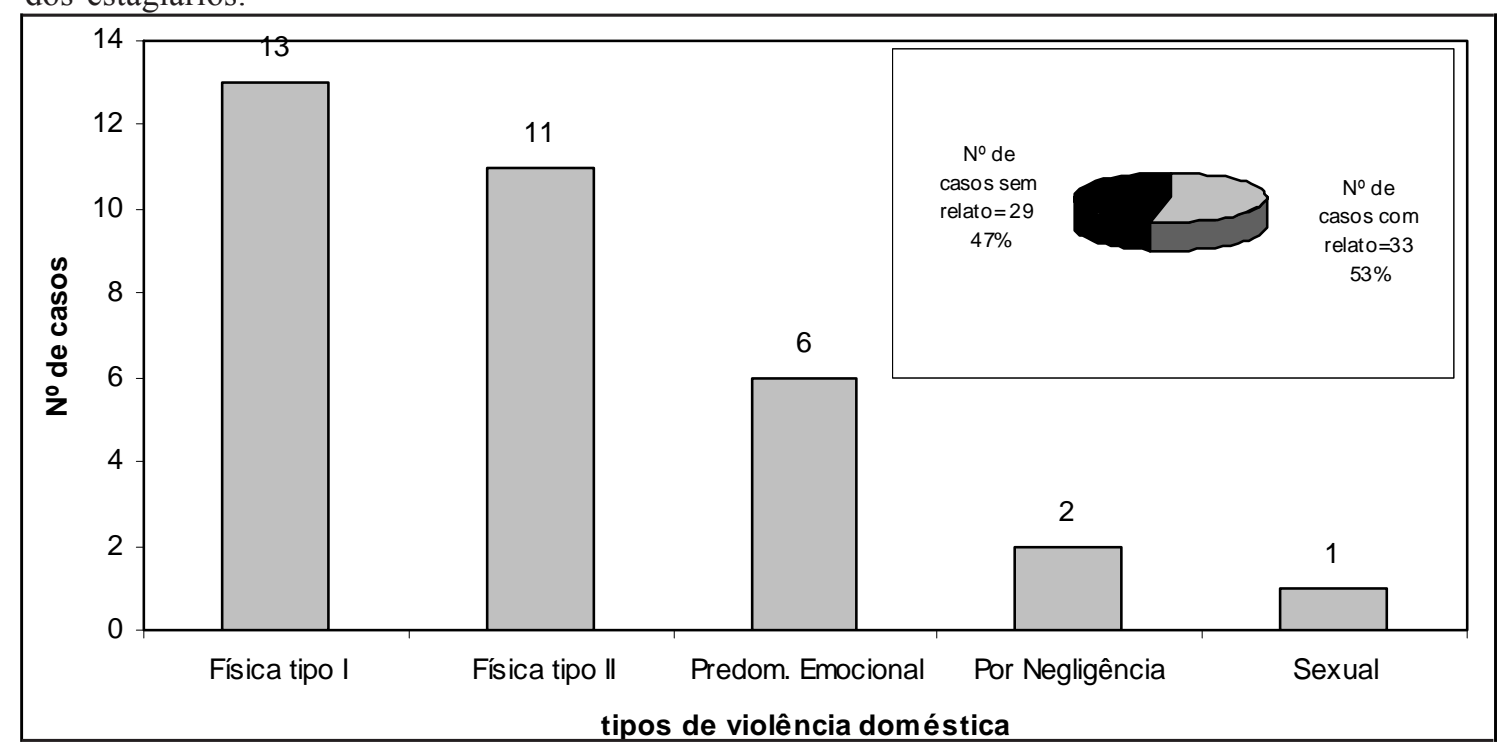


A Figura 4 apresenta a freqüência dos principais tipos de violência doméstica identificados nos casos analisados, de acordo com os registros e relatos dos estagiários.

\section{DISCUSSÃO}

Analisar as características sócio-demográficas da população infanto-juvenil é importante pois elas são indicadores que podem ajudar na compreensão de fatores relacionados à instalação e à manutenção de muitos dos comportamentos apresentados como queixa aos serviços de atendimento em Psicologia, podendo orientar o planejamento dos procedimentos de intervenção. Alguns destes fatores dizem respeito ao gênero, à ordem de nascimento e ao número de fillhos da família, ao local de moradia, à escolaridade e ocupação do cuidador principal de crianças e adolescentes e à própria estrutura da família nuclear, conforme foi destacado nos resultados obtidos neste estudo, os quais serão discutidos a seguir.

Como já mostrado em estudos anteriores, a maioria da clientela infanto-juvenil que chegou ao atendimento no serviço de Psicologia Pediátrica do HU era do sexo masculino. No estudo realizado por Marinho e col. ${ }^{3} \mathrm{o}$ índice de meninos encaminhados para atendimento chegou a $68,7 \%$, similar ao encontrado neste estudo (68\%). No trabalho de Bernardes-daRosa e cols. ${ }^{8}$, entretanto, apesar do número de meninos também ter sido superior $(60 \%)$ ao de meninas (40\%), a diferença não foi considerada significativa por esses autores.

Neste estudo, observou-se que, em todas as faixas etárias, com exceção da entre 15 e 17 anos, o número de meninos foi superior ao de meninas, especialmente no intervalo de 3 a 6 anos de idade. A análise deste resultado sugere a importância de se considerar outras variáveis em correlação ao gênero e à faixa etária, como o início da escolaridade. Sabe-se que nesse período a criança está se adaptando ao contexto escolar, ampliando seu ambiente social ao interagir com outros indivíduos, além de iniciar o processo de educação formal. Neste contexto, é freqüente professores (representando a comunidade) chamarem a atenção da família para as dificuldades do comportamento da criança, como problemas de aprendizagem e dificuldades em habilidades sociais, solicitando atendimento especializado, como aconteceu em alguns dos casos analisados neste estudo.

Outra questão a ser considerada acerca do alto índice de meninos atendidos pode estar relacionada a questões culturais, pois se observou uma maior permissividade dos pais em relação a filhos do sexo masculino, conforme análise dos registros obtidos nos protocolos de resumo dos atendimentos, favorecendo uma maior freqüência de comportamentos opositores e os relacionados à agressividade entre os meninos. Caberia futuramente a realização de uma investigação mais acurada sobre as diferentes práticas parentais dirigidas a meninos e a meninas que procuram o atendimento em psicologia.

Além da diferença no gênero, a proporção de filhos caçulas submetidos ao atendimento foi superior ( $43 \%$ ) às demais ordens de nascimento, não confirmando resultados de estudos realizados na área. No estudo conduzido por Marinho e col. ${ }^{3} \mathrm{o}$ índice de fillhos primogênitos chegou a $75 \%$, diferente dos achados do presente estudo, o que pode ter relação com uma outra questão, que será abordada adiante, acerca da ausência de limites. Seria possível considerar que os pais estariam mais permissivos com o último filho de sua prole? Rigores e exigências poderiam ter sido mais utilizados com os primeiros filhos? Por outro lado, o número de participantes primogênitos (34\%) foi mais elevado do que os casos de filho único (13\%). Talvez a ordem de nascimento não seja o fator mais significativo na condução da educação dos filhos, mas sim o número de filhos, pois pode-se supor que quanto maior a prole, maior a dificul- 
dade de administração dos cuidados e atenção dos pais aos filhos.

Com relação à escolaridade da população infanto-juvenil atendida durante o período em que este estudo foi realizado, os dados indicam aspectos positivos, pois todos os que estavam em idade escolar segundo os critérios utilizados na análise, estavam matriculados em escolas, tendo a maioria relatado uma boa freqüência às aulas, exceto uma criança de quatro anos que ainda não havia iniciado sua escolarização. Embora se suspeite de que a qualidade do ensino ao qual estas crianças e adolescentes estavam sendo submetidos estivesse aquém do direito à uma boa educação formal, considerase este resultado como positivo, indicando preocupação das famílias em oferecer oportunidade de formação acadêmica para seus filhos.

Nesse sentido, um aspecto a ser discutido refere-se à quantidade superior de crianças e adolescentes que estão em séries compatíveis com sua idade cronológica. Estima-se que este dado reflita mais o modelo de educação que vem se estruturando nas propostas governamentais de ensino fundamental, nas quais não há reprovações, uma vez que o aluno pode avançar de série tendo o direito de receber apoio pedagógico naquelas disciplinas em que não obteve desempenho satisfatório. É interessante notar que, apesar do elevado índice de correspondência entre nível de escolaridade e idade, as queixas de dificuldades escolares são bastante elevadas, presentes em 35 dos casos (Figura 3), sendo que em 29 aparece como queixa principal. Como exemplo, temos o caso de um menino de 10 anos, cursando a $4^{\mathrm{a}}$ série, com queixas de dificuldades de adesão ao tratamento de asma, e problemas conjugais entre os pais. Tinha histórico de notas escolares satisfatórias. Em um dos atendimentos foi solicitado que esta criança realizasse uma leitura. No decorrer da atividade, a estagiária observou que o menino não ficava sob controle das regras de pontuação e apresen- tava pouca compreensão sobre o material lido, sugerindo que o mesmo teria dificuldades para acompanhar as disciplinas escolares.

A análise destes resultados permite discutir a necessidade que o atual serviço de Psicologia Pediátrica do HU tem de realizar parcerias com profissionais da área da educação, em especial com o curso de Pedagogia. Isto poderia favorecer a realização de avaliações pedagógicas mais qualificadas, além de auxiliar em estratégias de intervenção na área escolar, como sugere o modelo sistêmico extensivo à escola apresentado em Silvares ${ }^{2}$. Em dois casos, ambos com queixa de hiperatividade, foram feitas intervenções junto às escolas, as quais mostraram-se importantes na evolução e andamento dos casos.

Com relação à moradia, a grande maioria dos participantes é residente na cidade de Belém (71\%), em bairros próximos ao HU (61\%). Este dado permite inferir que a maioria da população atendida é de baixa renda, haja vista que grande parte destes bairros constitui área de invasão, havendo grande incidência de violência, não dispondo de saneamento básico etc.

O levantamento de dados acerca do local de moradia dos participantes é importante na medida em que pode fornecer pistas sobre as condições ambientais às quais a criança está inserida. Por exemplo, é importante saber se no local há áreas de lazer adequadas, saneamento básico satisfatório e condições de segurança para o desenvolvimento de crianças e adolescentes. Neste estudo, a maioria da clientela atendida não tinha acesso a esses benefícios. Além disso, o local de moradia também pode influenciar na qualidade do relacionamento familiar, o que pode estar associado às queixas de violência doméstica (principais ou secundárias) identificadas nos casos estudados.

Os dados acerca do cuidador principal indicam que a responsabilidade e os cuidados básicos em relação ao filho estavam sendo realizados predominantemente pela mãe biológica 
(73\%), o que permite questionar se esta cuidadora dedicava a maior parte do seu tempo conciliando os afazeres domésticos e os cuidados com os filhos, pois, como apresentado nos resultados, a ocupação de 23 dos cuidadores foi considerada "do lar" $(37,1 \%)$, sendo esta a ocupação mais freqüente neste estudo. Supõese que parte destas mães cuidadoras principais também dividiam os cuidados com os filhos com alguma outra ocupação. Isto sugere que orientações parentais destinadas à mãe "do lar" poderiam ser generalizadas beneficiando também a relação estabelecida com os outros filhos e com cuidadores substitutos.

O nível de escolaridade do cuidador principal concentrou-se no ensino fundamental incompleto $(n=15)$, havendo também uma equiparada quantidade de cuidadores com ensino médio completo $(\mathrm{n}=14)$. Porém, 15 dos cuidadores não informaram a escolaridade, o que dificulta uma análise mais precisa. A relevância da escolaridade do cuidador para a qualidade do relacionamento entre pais e filhos é refletida na medida em que quanto maior a escolaridade, menor os ricos para a criança, pois estudos indicam que há correlação positiva entre anos de escolaridade, especialmente da mãe, e qualidade nos cuidados dispensados às crianças.

Quanto à situação conjugal dos pais, biológicos ou adotivos, o número de casados $(n=28)$ esteve próximo ao número de separados $(n=24)$, indicando que houve um número significativo de crianças e adolescentes inseridos em ambientes diferentes daqueles constituídos pelos membros da família nuclear tradicional - pai, mãe e filhos. Este número eleva-se ao serem contabilizados os viúvos $(n=4)$. Estes dados podem indicar que as mães estão assumindo tanto o arrimo de família como o apoio emocional aos filhos. Este desmembramento familiar chama a atenção ainda para a questão da violência, discutida adiante. Caberia uma investigação acerca da possível relação entre nível de escolaridade do cuidador, situação con- jugal e índices de violência.

Com relação à procedência dos atendimentos, observou-se que a maioria dos casos era de demanda interna (58\%), significando que essa parcela de crianças e adolescentes já era usuária dos serviços disponibilizados pelo HU. A maioria estava em consulta pediátrica quando o profissional identificou necessidade de acompanhamento psicológico e encaminhou o paciente ao serviço de psicologia pediátrica $(\mathrm{n}=13)$.

Uma outra importante fonte de encaminhamento foram as atividades em "sala de espera" as quais eram realizadas pelo próprio serviço de psicologia pediátrica visando a divulgação e oferta do serviço aos usuários do HU, destacando-se as realizadas com os pacientes aguardando consulta na neuropediatria e na alergologia.

Houve ainda uma significativa parcela daqueles que procuraram pelo atendimento espontaneamente, sem encaminhamento formal de profissionais do HU (26\%), o que indica a referência do serviço de psicologia e reconhecimento da importância deste profissional, considerando-se a grande procura pela divisão de psicologia do HU, mesmo por uma população de baixo poder aquisitivo, não sustentando a concepção de a Psicologia como um serviço "elitizado". Através dessa análise, é possível considerar que, quando o serviço está disponível e é divulgado, as pessoas buscam pelo atendimento. Nesse sentido, os atendimentos desenvolvidos em contextos de sala-de-espera têm grande relevância para a divulgação do serviço, bem como para o atendimento específico de pré-consulta aos pacientes do HU.

Dos casos atendidos, $16 \%$ foram encaminhados por outros órgãos e serviços externos ao HUBFS, como programas do Hospital da Fundação Santa Casa de Misericórdia, Conselho Tutelar, Coordenação Estadual de Educação Especial (COEES) e escolas da comunidade, indicando a necessidade de estruturação 
do serviço no sentido de tentar delimitar a clientela a ser atendida, priorizando determinados casos e encaminhando outros às duas clínicasescola existentes na cidade de Belém. Para tanto se faz necessário o estabelecimento e oficialização de parcerias com os serviços oferecidos nessas universidades.

No decorrer dos atendimentos, o serviço também efetuou diversos encaminhamentos a várias especialidades e programas disponíveis no HU e fora dele, sugerindo a relevância do estagiário estar atento a outras variáveis além daquelas consideradas estritamente de "origem psicológica". Além disso, os dados confirmam a relevância de uma rede de apoio e serviços que possam beneficiar ainda mais o usuário.

Na Figura 2, nota-se que o número de encaminhamentos destinados ao grupo de pais "Conviver", bem como o número de comparecimentos a esse destino, foi elevado, ressaltando a importância de grupos de orientação a pais, pois a troca de experiências também é uma importante variável no processo de mudança nas interações entre pais e filhos, conforme sugerem os estudos de Marinho e col. ${ }^{3}$ e Bernardes-da-Rosa e cols. ${ }^{8}$.

Foram amplas e diversificadas as queixas relatadas e investigadas ao longo dos atendimentos. A partir da categorização das queixas mais freqüentes, os resultados obtidos revelaram que 48 casos apresentavam dificuldades em habilidades sociais, manifestadas de diferentes formas, como comportamentos opositores, agressividade, rebeldia, pouca interação social, medos etc., corroborando os achados da literatura, que também indicam elevados índices de distúrbio de comportamento explícito assim como alto número de queixas de dificuldades escolares como no estudo de Beranrdesda-Rosa e cols. ${ }^{8}$.

Uma importante situação de risco à criança e ao adolescente encontrada neste estudo refere-se à violência doméstica. Nota-se que ela não é relatada como queixa principal, ca- racterizando-se mais como uma relevante variável investigada no transcurso dos atendimentos, na medida em que é, muito provavelmente, a principal forma que a família utiliza para controlar, conter, corrigir e punir aqueles comportamentos considerados inadequados e trazidos como queixas principais para o atendimento. Entretanto, esta forma de controle coercitivo pode ser uma das principais variáveis instaladoras e mantenedoras dos comportamentos relatados como queixa principal, como sugere Alvarenga ${ }^{5}$, uma vez que somente cinco dos 33 casos com relato de violência doméstica apresentaram-na como queixa inicial.

Através dos registros dos atendimentos realizados e das entrevistas conduzidas com os estagiários notou-se ainda que muitas das dificuldades enfrentadas pelos pais na educação dos filhos estavam relacionadas à dificuldade no estabelecimento de limites, o que reforça a importância da continuidade dos grupos de pais assim como da constante orientação a pais somada à psicoterapia individual, como apontam os estudos sobre educação infantil ${ }^{3}$. O demasiado uso de controle coercitivo, associado à dificuldade dos pais em estabelecer limites na educação dos filhos pode estar corroborando princípios da Análise do Comportamento os quais sustentam que os efeitos imediatos da punição explicam a manutenção desta prática educativa pelos pais; entretanto, a longo prazo pode-se observar o reaparecimento do comportamento punido, muitas vezes associado a efeitos nocivos como comportamentos emocionais inadequados (timidez, ansiedade, desamparo, agressividade) ${ }^{6}$.

\section{CONCLUSÃO}

A grande variedade de queixas sugere a necessidade de sistematização do serviço, a partir de uma melhor estruturação dos atendimentos para que um serviço especializado possa aumentar 
a qualidade ofertada aos usuários. Para tanto, faz-se necessário estabelecer critérios para os encaminhamentos. Foi observado que, as guias de encaminhamento fornecidas pelos profissionais do HU e destinadas ao serviço de Psicologia Pediátrica apresentavam indicativos superficiais e pouco explicativos que justificassem, de fato, o próprio encaminhamento.

Pode-se apontar igualmente o uso de controles coercitivos prejudiciais à qualidade de vida de crianças e adolescentes, bem como ao desenvolvimento de padrões de in- teração mais saudáveis entre pais e filhos, sendo possível ampliar a importância da análise da categoria violência doméstica na medida em que ela pode estar estreitamente relacionada às outras categorias de queixas apresentadas.

\section{Agradecimento}

Este estudo foi realizado com o apoio do Hospital Universitário Bettina Ferro de Souza, da Universidade Federal do Pará.

\begin{abstract}
The present work is a descriptive study presenting a characterization of complaints identified in children and teenagers $(\mathrm{N}=62)$ assisted by the Pediatric Psychology service of a university hospital. A survey of socio-demographic indicators of the children and teenagers, as well as of their caregivers, was carried out. A descriptive statistical analysis regarding the care that was given was accomplished, considering items such as the origins of the population, provided directions, and the most frequent complaints (primary and secondary). It was verified that some findings corroborate the previous literature, such as the high number of boys seeking the service, the rate of treatment abandonment, and similar kinds of complaints. An excessive use of coercive practices by parents was also observed, which points to the domestic violence issue. These findings were preliminary and may contribute to the implementation of a more structured Pediatric Psychology service, as well as subsidize further research using correlational statistical analyses.
\end{abstract}

Key-words: pediatric psychology; children and adolescents; caregivers; socio-demographic indicators; domestic violence.

\section{REFERÊNCIAS}

1. Conte FCS, Regra JAG. A psicoterapia comportamental infantil: novos aspectos. In: Silvares EFM, organizador. Estudos de caso em psicologia clínica comportamental infantil. Campinas: Papirus; 2000. v. 1; p. 79-136.

2. Silvares EFM. O modelo triádico no contexto de terapia comportamental com famílias. Psicol Teor Pesqui. 1995;11(3):235-41.

3. Marinho ML, Silvares EFM. Modelos de orientação a pais de crianças com queixas diversificadas. In: Wielenska RC, organizador. Sobre comportamento e cognição. Santo André: ARBytes; 2000. p. 171-85.

4. Marinho ML. A intervenção clínica comportamental com famílias. In: Silvares EFM, organizador. Estudos de caso em psicologia clínica comportamental infantil. Campinas:
Papirus; 2000. v. 1; p. 139-74.

5. Alvarenga P. Práticas educativas parentais como forma de prevenção de problemas de comportamento. In: Guilhard HJ, Madi BM, Queiroz PP, Scoz MC, organizadores. Sobre comportamento e cognição. Santo André: ARBytes; 2001. p. 54-60.

6. Sidman M. Coerção e suas implicações. Campinas: Livro Pleno; 2001.

7. Canaan-Oliveira S, Neves MEC, Silva FM, Robert EAM. Compreendendo seu filho: uma análise do comportamento da criança. Belém: Paka-Tatu; 2002.

8. Bernardes-da-Rosa LT, Garcia RM, Domingos NAM, Silvares EFM. Caracterização do atendimento psicológico prestado por um serviço de psicologia a crianças com dificuldades escolares. Estud Psicol (Campinas). 2000;17(3):5-14.

9. Zannon, CMLC. Psicologia aplicada à pediatria: 
questões metodológicas atuais. In: Kerbauy RR, organizador. Comportamento e saúde: explorando alternativas. Santo André: ARBytes; 1999. p. 46-58.

10. Hospital das Clínicas da Faculdade de Medicina de Ribeirão Preto [homepage na internet]. [Acesso em 05 ago 2003]. Disponível em: http://www.hcrp.fmrp.usp.br.

11. Hospital Universitário de Brasília [homepage na internet]. [Acesso em 05 ago 2003]. Disponível em: http://www.hub.unb.br.

12. Hospital das Clínicas da Faculdade de Medicina da Universidade de São Paulo [homepage na internet]. [Acesso em 11 ago 2003]. Disponível em: http://www.hcnet.usp.br.

13. Hospital Universitário Oswaldo Cruz [homepage na internet]. [Acesso em 11 ago 2003]. Disponível em: http://www.huoc.upe.br.

14. Roberts MC. Introduction to pediatric psychology: an historical perspective. In: Roberts MC, Koocher GP, Routh DK, Willis OJ, organizadores. Readings in pediatric psychology. New York (NY): Plenum Press; 1993.p. 1-39.

15. Pastoral da Criança. A paz começa em casa. Brasília(DF): CNBB; 1999.

Recebido em 21/09/2005 Modificado em 28/12/2005 